\title{
THE EFFECTIVENESS OF CHUNKING METHODS FOR ENHANCING SHORT-TERM MEMORY OF TEXTUAL INFORMATION
}

\author{
${ }^{1}$ Piwat Suppawittaya, ${ }^{2}$ Pratchayapong Yasri \\ ${ }^{1}$ Bangkok Christian College, Thailand \\ ${ }^{2}$ Institute for Innovative Learning, Mahidol University, Thailand
}

\section{ABSTRACT}

The effectiveness of students' memorization of textual information was investigated in this study with 50 high school students. The information was presented to the participants in three different types: 10 distinct alphabets, 10 distinct numbers, and a combination of 5 distinct alphabets and 5 distinct numbers. This information was divided into three different chunking methods: One-Chunk where the whole information was told all at once, Two-Chunks where the information was divided into 5 and 5 , and Three-Chunks where the information was delivered in 3-3-4, 4-3-3, and 3-4-3 fashions. The statistical results revealed that a single type of information (either all alphabets or all numbers) was found to be easier to recall than the combined information. Furthermore, dividing the information into two or three chunks was found to enhance human memorization more significantly. In addition, the study showed that when a combined type of information was shown, grouping the information into two chunks was more effective to enhance short-term memory than providing it in one chunk. Educational implications can be drawn from this study that in order to assist students to memorize and retain learning materials more effectively, it is essential to help classify them into 2-3 groups when being delivered. Also, learning should emphasize more on how to help students learn to take in information more effectively by themselves through the use of tree thinking, binary thinking, and computational thinking.

Keywords: Cognitive Information Processing (CIP), Short-term memory, Chunking, Textual information

\section{Introduction}

Whether human short-term memory is specifically designed to process certain types of information and there is an effective way to facilitate memorization by utilizing extrinsic factors are issues of interest. Although the origin, pathway, and usage of shortterm memory has been extensively studied, people's stereotypic preference to the use of "three things" to engage others and to help others to remember key messages remains ambiguous. Examples for this are "please give me three words to describe yourself" or "sit back, relax, and enjoy the show", or 3-point sermons. The rationale behind three-point sermon which is a dialectical teaching method originally designed as a non-emotional discussion between two scholars (Kruger, 2008) despite being frequently used (Tomlin, 2020), is unclear and equivocal. In fact, it is also unexplainable how people often choose or are required to use three adjectives to define themselves. Interestingly, despite the fact that most people find the occurrence relatable to their daily life, it has never been taught or guided to follow.

We therefore coin the term "Three-Chunk effect" to explain this phenomenon. More examples could be given here to provide evidence that this Three-
Chunk effect is predominantly used. Ample among others is the fact that the majority of Thai people instinctively choose to remember their 10-digit phone number in three chunks: three digits in the first chunk, another three in the second chunk, and the last four in the final chunk (called a 3-3-4 pattern) such as 0926918786 . This is also apparent in the business industry that numerous famous brands use only two or three words in their slogans to hook customer's attention. To be more precise, BMW's "Sheer Driving Pleasure"(Vigneron \& Johnson, 1999), EA's "Challenge Everything" (Lauwaert, 2007), Audi's "Never Follow" (Mahmood, 2009), Adidas's "Impossible is Nothing” (Jian-jun, 2010), Tesco's “Every Little Helps" (Nemÿoková, 2011), Skittles's "Taste the Rainbow” (Sokolovsky, 2012), Jaguar's “Grace, Space, Pace" (Michalik\&Michalska-Suchanek, 2016), Apple's “Think Different” (Tasnim, 2018), Volkswagen "Think small" (Alnajjar, et al., 2018)and Nike's “Just do it" (Wells, 2019)are only ten of the many global brands that follow this effect.

Regarding all of the instances, it is believed that chunking certain types of information would be able to reach short-term memory and eventually being added into long-term memory quick than others. In fact, it would lead additional insights of strategies 
that teachers should take into consideration in which is found to enhance their student's memorization, thus, increasing the chance of students' understanding of certain subjects and knowledge.

Therefore, the aim of this study is to compare the effectiveness of different types of information to be processed into short term memory. Furthermore, this research focuses on determining the effectiveness of each chunking method by grouping the same quantity of information into different numbers of chunks which have different numbers of items in each chunk. It is hypothesized that information that is not complicated and has an appropriate number of chunks and number of items per chunk would be easier to recall than those that are sophisticated and are provided in merely one chunk. Thus, it would be compatible with the Three-Chunk effect mentioned earlier and would portray a clear picture of the human memory system and how to effectively provide information to maximize students' learning ability. Lastly, the research would open doors to further research in order to find the optimal way to chunk methods for different types of information and elaborate the human memory model more precisely.

\section{Literature Review}

The Cognitive Information Processing (CIP) theory is a well-renowned framework in cognitive psychology thatisapplied to illustrate the human memory system. By adopting the multi-store model from Shiffrin \& Atkinson (1969) in which they used a computer metaphor with its inputs and outputs to locate sensory memory, short-term memory (STM) and long-term memory (LTM) are considered three main parts in the system. These three keywords are clearly defined by Schunk (1996). Sensory memory holds information associated with senses such as visual and auditory for a short period of time (in seconds) before the information is processed further. Then short-term memory functions or working memory further processes the carried information and with regular rehearsal, it is ready for long-term storage or for a response. Lastly, the information in humans' long-term memory is permanent and capable of retaining information in numerous ways. Moreover, another study had brought the flowchart and added certain steps that must be performed for the information to be remembered in human's memory: attention, rehearsal, chunking, encoding and retrieval (Driscoll, 1994) as shown in Figure 1.

When an information, or sensory input is shown and reaches the sensory memory, one must pay attention or have content of awareness for the information to be processed to the short-term memory (Cowan, 1993; Deco \& Rolls, 2005; Wang, et al., 2018). Then in order for the information to remain in the short-term memory for some designated period of time, maintenance rehearsal which refers to the repetition of information must be performed (Gathercole \& Hitch, 1993; Tallon-Baudry, et al., 2001; Jing, et al., 2019). However, maintenance rehearsal is not sufficient for intricate or meaningful information to reach long-term memory. This can be accomplished through elaborative rehearsal, which is also known as encoding. (Phaf\&Wolters, 1993; Todd \&Marois, 2004; Mitchell \& Hill, 2019). After the informationis encoded into long-term memory, the process of retrieval is required to utilize learned information to either apply it to grasp new knowledge or make a response (Anderson, et al., 1994; Pignatelli, 2019). To be precise, two main types of retrieval were mentioned by Hintzman\& Curran (1994) and Caruso, et al., (2020): recall is when the information that is retrieved do not have any strategies to help remembering, and recognition is when the information that is attached to stimuli such a hint or choice that was previously provided. Furthermore, in some occasions, the information can be forgotten in the human memory system. In shortterm memory, forgetting could occur from decay that could occur mere seconds after being informed, whereas in long-term memory forgetting could occur from failure of retrieval and minimal usage of the information over a long period of time. (Barrouillet, 2013). 


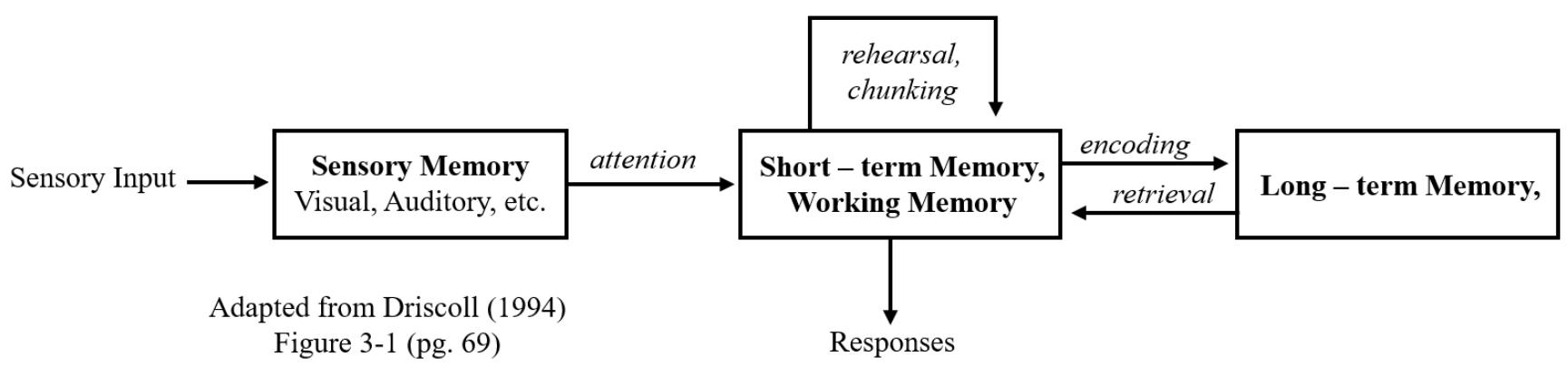

Figure 1 - Multi-store Model according to CIP Theory

Regarding this flowchart, a number of research studies adopt it as a model to enhance student's education, for example in elements of a science of e-learning (Mayer, 2003) and the effect of using PQ4R (Preview, Question, Read, Reflect, Recite, Review) strategy on EFL Students' Reading Comprehension Achievement (Martina, 2018)

Focusing on short-term memory, it is primarily differentiated from long-term memory by James (1890) who state that they are qualitatively different and is later confirmed by Hebb (1949). However, while numerous studies reveal that patients with parietal and temporal lobe damage have impaired short-term memory but normal long-term memory (Shallice \& Warrington, 1970) which was the opposite to those with medial temporal lobe damage (Baddeley \& Warrington, 1970), a metanalysis that compares regions during verbal longterm memory and short-term memory tasks indicate a significant overlap in neural activation (Cabeza \& Nyberg, 2000). Thus, one explanation that could exemplify the ambiguity if this fact is that certain neuroimaging tasks of short-term memory often uses longer retention intervals (Buffalo, et al., 1998). In spite of this confusion between the two memory storages, one study reports that the medial temporal lobe is uniquely activated for only long-term memory (Talmi, et al., 2005).

Moreover, a later study points out that short-term memory and long-term memory differ in theirduration and capacity. It is believed that an item that is told in the same time interval with others is found to be more difficult to recall because it shares their temporal cues to retrieval (Cowan, 2008). Thus, when the list of subjects is told, short-term memory would most likely remember the most distinct temporally. Also, Darwin \& Crowder, (1972) and Vogel \& Luck (2006) also report in the same way that the limit of the focus of attention for numbers of items in each chunk is between three and four items.

From then on, there are various studies attempting to explain the mechanism of short-term memory but Baddeley \& Hitch (1974)'s working memory model is found to be the best depiction. The model contains four main components: central executive, visuospatial sketchpad, episodic buffer and verbal buffer, which are all separated from long-term memory. A central executive is responsible for organizing the interplay between the aforementioned buffers and the long-term memory and is activated when the information is being processed (Baddeley, et al., 1986). A visuospatial sketchpad is designed to store visual information that can be further simplified into object and spatial stores (Smith, et al., 1995). An episodic buffer draws on the other buffers and short-term memory has been added to account for the control of multimodal information (Baddeley, 2000). Finally, a verbal buffer or phonological loop is assumed to hold information that can be rehearsed verbally including letters, digits (Repovš\&Baddeley, 2006). With these four components, there are many researchers studying more about working memory, and most of them include citations to Alan Baddeley (Jonides, et al., 2008)

One of the main topics that is found to adopt the findings of short-term memory is associated with verbal buffers (Shallice\&Papagno, 2019). Since then, a portion research in the field of neuropsychology are focused on letters and numbers memory mechanism, for example, Down syndrome memory deficit (Jarrold\&Baddeley, 2001), language processing (Baddeley, 2003), childhood vocabulary and number skills (Gathercole, et al., 2005), reading, writing, mathematics, speaking and listening, and personal and social development (Alloway, et al., 2005), vocabulary development in children (Majerus, et 
al., 2006), and lexical learning in bilingual adults (Majerus, et al., 2008). Although Miller's (1956) theoretical review of a "magical number seven, plus or minus two" is probably the most seminal paper in the literature for investigations of limits in short-term memory storage capacity, human's memorization process remains ambiguous. The explanation behind how letters and numbers work in short term memory is initiated by Sperling (1960) in which the same strand of research has also been done by others (Kroll, et al., 1970; Garavan, 1998; Parrila, et al., 2004; McElree, 2006).

Sperling'sexperiment was conducted by visually presented arrays of characters for a 50-second period and was followed by a blank screen. Then the results which were the array the subjects were required to be recalled in a written form. Moreover, it was suspected that subjects could not attend to so many items in such a brief time but used the sensory memory outlasted the brief stimulus array, and that items could be recalled to the extent that the information could be extracted from that preattentive store. Sperling's results reveal that when the cue occurs very shortly after the array, most or all of the items could be recalled, but that diminishes as the cue delay increases. Although his terminology or "sensory memory" is not exactly accurate, it is moving towards the precise explanation (Phillips, 2001). In fact, it is compatible with the role of short-term memory as when information in letters and numbers is activated, it merely remains activated automatically for a short period of time or about 2 - 30 seconds (Cowan, 1984).

After that decaying from activation unless it is reactivated during that period through additional, related stimulus presentations or thought processes which is in the form of the phonological buffer or the visuospatial sketch pad (Baddeley, et al., 1998).In a longer period of time, as mentioned earlier rehearsal is compulsory for the information to be implanted in one's short-term memory (Wilding, 2001). Rehearsal is the process of thinking of an item over and over and thereby keeps it accessible to the focus of attention (Cowell, 2001). For instance, in a number memory test, participants might rehearse a sequence such as " $1,9,3,8,6$ " while using the focus of attention to accomplish other portions of the task (McElree\&Dosher, 2001), that could be articulated in about 2 seconds (Murray, 2001). Interestingly, a previous research from Guttentag's (1984) memory tests suggested that as children mature, they would be able to rehearse certain information with less attention while performing continuous tasks.
Other than relying entirely on humans' memory to remember letters and numbers, a strategy called "chunking" which is a process of grouping the presented information to effectively compress the context (Schneider, et al., 2001) is considered one of the bestknown methods of increasing the amount of information stored in memory (Lane, et al., 2001). Chunking can occur in two different ways: either through strategic reorganization based on familiarity or prior knowledge (often used in letters and numbers), or through grouping based on perceptual characteristics (often used in visuals) (Gobet, 2005). Miller (1956) is also the person who first points out that information can be categorized in meaningful units, namely chunks, which can increase the amount of recalled information and immediate memory span. However, at that period of time, it was still ambiguous on how chunks accurately reflected the internal cognitive processes (Gilchrist \& Cowan, 2011). As a result, many researchers attempt to enhance the validity of chunking, for instance Tulving\&Patkau (1962) who commented that it would be not accurate for researchers to compare information that was classified into chucks that used to be bounded together with ones that were primarily unrelated. Thus, it was later agreed that items recalled from the same presented unit must be grouped together as one chuck (Chen \& Cowan, 2019). In addition, each chunk must be limited to an appropriate number of items in order to maintain its effectiveness. Otherwise, it would be similar to simply not undergoing chunking as most people were likely to remember the information at the beginning and at the end (Lorenz \& Tizón-Couto, 2019). In the upcoming future, behavioral and neuropsychological, and modeling methods must be integrated to further improve methods of chunking in order to maximize human's memorizing potential (Gilchrist. 2015).

Therefore, it is perceptible that although extensive numbers of researches are trying to portray the full picture of the human memory system, the experiments and explanations about chunking patterns and the comparison between the effectiveness the human's memory to memorize letters, numbers and a combination of these two aforementioned types are still limited. Hence, this research will be focusing on comparing the effectiveness of working memory when retrieving different forms of information, the effectiveness of working memory when retrieving information in different "chucking" methods, and the optimal way to split three chucks of information. 
Methodology

\section{Data Collection}

As this research focused on studying human's short-term memory through an evaluation of letters and numbers, it was divided into three main parts: Letters (10 randomly selected distinct alphabets ranging from A - Z), Numbers (10 randomly selected distinct one-digit numbers ranging from 0 - 9), and Combined (5 randomly selected distinct alphabets and numbers arranged alternatively starting from a letter). The alternation between letters and numbers was regarded as the "Trail Making Test" (TMT) that was initiated by Parington \& Lieter (1949). This method was commonly used in the field of neuropsychology, including to evaluate whether the complexity of Arabic orthography increases its perceptual load, thus slowing word identification (Ibrahim \& Aharon-Peretz, 2002) and to confirm the test-retest reliability and validity of the National Center for Geriatrics and Gerontology functional assessment tool (NCGG-FAT) for community-dwelling older adults (Makizako, et al., 2013)

Moreover, each part required five trails which all undergo different chunking methods: One-Chunk (all alphabets and digits were told continually without any spacing), Two-Chunk(5 alphabets and digits were told with a spacing, followed by the other 5), Three-Chunkwhich consisted of three ways: a) $\mathbf{4 + 3 + 3}$ (4 alphabets and digits were told with a spacing, followed by another 3 with a spacing, and then the last 3), b) $\mathbf{3 + 4 + 3}$ (3 alphabets and digits were told with a spacing, followed by another 4 with a spacing, and then the last 3 ), and c) $3+3+4$ (3 alphabets and digits were told with a spacing, followed by another 3 with a spacing, and then the last 4). As mentioned earlier, the rationale behind the chunking these 10 letters and numbers was from Cowan (2001), Gobet \& Clarkson (2004), and Mathy \& Feldman (2012) who all reported in the same direction that the number of chunks that could effectively be stored in short-term memory should be limited to four or fewer items. Hence, the experiments were only divided up to three chunks.

Due to the current COVID-19 pandemic, the method of conducting experiments was designed to be entirely online. An evaluation form was created in .pdf form and was sent to each participant before undergoing the experiments in order for them to open the file and edit it on their iPad. All of the experiments were conducted individually through a video call on a laptop to guarantee that they were strictly following instructions. In addition, a short demo recording of letters and numbers was played to the participants to ensure a stable internet connection and clear audio quality. Furthermore, all of the 15 recordings (5 each for Letters part, Numbers part and Combined part) were played through an iPad and each participant was required to listen to one whole recording before attempting to write their answers. Every recording was merely played once and the pattern of the experiments was identical for every participant, starting from the Letters part, Numbers part and lastly combined part. Also, the participants were required to use their headphones and mute their microphones while each of the recordings was played to avoid any sound echoing. The answers in letters are told to be written to upper cases to avoid confusion between certain letters and numbers. After the experiments were finished, each participant would send their answers back to the researcher's iPad to be checked manually. Lastly, another revision of checking was performed before entering the results into categorized tables in Microsoft Excel to perform statistical analysis.

\section{Research Tools}

\section{a. Evaluation Form}

The evaluation form was a one-page .pdf that was divided into three main parts: Letters, Numbers, and Combined. Thus, it consisted of 15 rows, each of them had 10 blocks. A warning was performed to all participants about writing the results down in the correct block or otherwise it would be marked wrong. It was advised to simply write a hyphen in the blocks that contain no answer to avoid confusion and facilitate the researcher when checking them.(See Appendix A)

\section{b. Letters and Numbers in Experiments}

The letters and numbers in the experiments were brought from an online generator to minimize any human bias in arranging sequences of them. Then, they were revised to eliminate any group of letters and/or numbers that possess actual meaning or were abbreviations of something that might help the participants to memorize easier.

\section{Data Analysis}

After the results of 50 participants were collected, they were brought to perform T-tests using IBM SPSS Statistics 24 to find whether each value was significantly different to one another or not. The data were analyzed in three different ways to match the three research objectives; 1) compared the average number of correct 
answers between the Letters part, Numbers part, and Combined part, 2) compared the average number of correct answers from each chunking method within each part, 3) compared the average number of correct answers between Three-Chunk chunking methods of every part.

\section{$\underline{\text { Results }}$}

The table below is the mean of the correct answers in every trails of the Letters part, Numbers part, and Combined part from all 50 participants.

Table 1 Mean of correct answers in the Letters part, Numbers part, and Combined part $(\mathrm{N}=50)$

\begin{tabular}{lr|r} 
& & \\
& Mean & Std. Deviation \\
\hline Letter_OneChunk & 5.02 & 2.236 \\
\hline Letter_TwoChunks & 5.82 & 2.447 \\
\hline Letter_4_3_3 & 6.08 & 1.988 \\
\hline Letter_3_4_3 & 5.80 & 2.020 \\
\hline Letter_3_3_4 & 6.52 & 2.188 \\
\hline Number_OneChunk & 5.66 & 2.496 \\
\hline Number_TwoChunks & 5.64 & 2.414 \\
\hline Number_4_3_3 & 6.74 & 2.311 \\
\hline Number_3_4_3 & 6.14 & 2.424 \\
\hline Number_3_3_4 & 6.72 & 2.277 \\
\hline Combined_OneChunk & 5.12 & 1.976 \\
\hline Combined_TwoChunks & 6.04 & 1.884 \\
\hline Combined_4_3_3 & & \\
\hline Combined_3_4_3 & 5.10 & 2.297 \\
\hline Combined_3_3_4 & 5.62 & 2.230 \\
\hline Valid N (listwise) & 5.58 & 2.041 \\
\hline
\end{tabular}

As the research objectives and the data analysis contained three main parts, the results also were divided into three parts as followed which show mean comparisons at the significance level of $95 \%$.

1. Effectiveness of working memory when retrieving different forms of information
By comparing the average number of correct answers between the Letters part, Numbers part, and Combined parts and bringing them to perform T-tests, it was evident that the number of correct answers of the Numbers part was significantly different from that of the Combined part as shown in Table 2.

Table 2T-test of the average number of correct answers between each experiment $(\mathrm{N}=50)$

\section{Paired Samples Test}

\begin{tabular}{|c|c|c|c|c|c|c|c|c|c|}
\hline & & & & ed Differ & nces & & & & \\
\hline & & & $\begin{array}{c}\text { Std. } \\
\text { Deviatio }\end{array}$ & $\begin{array}{l}\text { Std. } \\
\text { Error }\end{array}$ & $\begin{array}{r}95 \% \mathrm{Co} \\
\text { Interva } \\
\text { Diffe }\end{array}$ & $\begin{array}{l}\text { fidence } \\
\text { of the } \\
\text { ence }\end{array}$ & & & Sig. (2- \\
\hline & & Mean & $\mathrm{n}$ & Mean & Lower & Upper & $\mathrm{t}$ & df & tailed) \\
\hline Pair 1 & $\begin{array}{l}\text { Letter_Average- } \\
\text { Number_Averag } \\
\text { e }\end{array}$ & -.3320 & 1.2990 & .1837 & -.7012 & .0372 & $\begin{array}{r}- \\
1.807\end{array}$ & 49 & .077 \\
\hline
\end{tabular}




\begin{tabular}{|c|c|c|c|c|c|c|c|c|c|}
\hline Pair 2 & $\begin{array}{l}\text { Letter_Average- } \\
\text { Combined_Aver } \\
\text { age }\end{array}$ & .3560 & 1.0477 & .1482 & .0583 & .6537 & 2.403 & 49 & .020 \\
\hline Pair 3 & $\begin{array}{l}\text { Number_Averag } \\
\text { e- } \\
\text { Combined_Aver } \\
\text { age }\end{array}$ & .6880 & 1.3292 & .1880 & .3102 & 1.0658 & 3.660 & 49 & .001 \\
\hline
\end{tabular}

2. Effectiveness of working memory when retrieving information in different "chucking" methods

When comparing the average number of correct answers from each chunking method within each part, the three Three-Chunk chunking methods trails (4-3-3, 3-4-3, 3-34) were brought to find the mean and compared with One-Chunk and Two-Chunk chunking methods. These results were divided into three main categories: a. Letters part, b. Numbers part, and c. Combined Part.

\section{a. Letters part}

After performing T-test, the results revealed that the number of correct answers of the Two-Chunk and ThreeChunk chunking methods weresignificantly different from that of the One-Chunk chunking method as shown in Table 3.

Table 3T-test of the average number of correct answers in Letters part $(\mathrm{N}=50)$

\section{Paired Samples Test}

Paired Differences

\begin{tabular}{|c|c|c|c|c|c|c|c|c|c|}
\hline & \multirow{2}{*}{\multicolumn{8}{|c|}{ Paired Differences }} & \multirow{4}{*}{$\begin{array}{l}\text { Sig. (2- } \\
\text { tailed) }\end{array}$} \\
\hline & & \multirow[b]{3}{*}{ Mean } & & \multirow{3}{*}{$\begin{array}{l}\text { Std. Error } \\
\text { Mean }\end{array}$} & \multirow{2}{*}{\multicolumn{2}{|c|}{$\begin{array}{l}95 \% \text { Confidence } \\
\text { Interval of the } \\
\text { Difference }\end{array}$}} & & & \\
\hline & & & \multirow{2}{*}{$\begin{array}{c}\text { Std. } \\
\text { Deviation }\end{array}$} & & & & \multirow[b]{2}{*}{$\mathrm{t}$} & \multirow[b]{2}{*}{$\mathrm{df}$} & \\
\hline & & & & & Lower & Upper & & & \\
\hline $\begin{array}{l}\text { Pair } \\
1\end{array}$ & $\begin{array}{l}\text { Letter_OneChunk- } \\
\text { Letter_TwoChunk } \\
\text { s }\end{array}$ & -.800 & 2.878 & .407 & -1.618 & .018 & -1.965 & 49 & .055 \\
\hline $\begin{array}{l}\text { Pair } \\
2\end{array}$ & $\begin{array}{l}\text { Letter_OneChunk- } \\
\text { Letter_ThreeChun } \\
\text { ks }\end{array}$ & $1.1133^{-}$ & 2.5050 & .3543 & -1.8252 & -.4014 & -3.143 & 49 & .003 \\
\hline $\begin{array}{l}\text { Pair } \\
3\end{array}$ & $\begin{array}{l}\text { Letter_TwoChunk } \\
\text { s- } \\
\text { Letter_ThreeChun } \\
\text { ks }\end{array}$ & -.3133 & 2.0597 & .2913 & -.8987 & .2720 & -1.076 & 49 & .287 \\
\hline
\end{tabular}

\section{b. Numbers part}

For the Numbers part, the results revealed that the number of correct answers of the Three-Chunk chunking methods was significantly different from that of the One-Chunk and Two-Chunk chunking methods as shown in Table 4.

Table 4T-test of the average number of correct answers in Numbers part $(\mathrm{N}=50)$

\section{Paired Samples Test}

Paired Differences

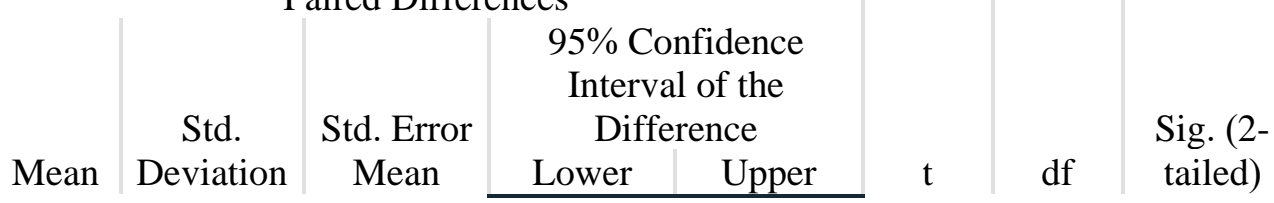




\begin{tabular}{ll|l|l|l|l|l|r|r|r}
\hline $\begin{array}{l}\text { Pair } \\
1\end{array}$ & $\begin{array}{l}\text { Number_OneChu } \\
\text { nk- } \\
\text { Number_TwoChu } \\
\text { nks }\end{array}$ & .020 & 2.766 & .391 & -.766 & .806 & .051 & 49 & .959 \\
\hline $\begin{array}{l}\text { Pair } \\
2\end{array}$ & $\begin{array}{l}\text { Number_OneChu } \\
\text { nk- }\end{array}$ & -.8733 & 2.5740 & .3640 & -1.6048 & -.1418 & -2.399 & 49 & .020 \\
\hline $\begin{array}{l}\text { Number_ThreeCh } \\
\text { unks }\end{array}$ & & & & & & & & \\
\hline $\begin{array}{l}\text { Pair } \\
3\end{array}$ & $\begin{array}{l}\text { Number_TwoChu } \\
\text { nks- } \\
\text { Number_ThreeCh } \\
\text { unks }\end{array}$ & -.8933 & 2.3000 & .3253 & -1.5470 & -.2397 & -2.746 & 49 & .008 \\
\hline
\end{tabular}

\section{c. Combined part}

For the Combined part, the results revealed that the number of correct answers of the Two-Chunk chunking method was significantly different from that of the One-Chunk and Three-Chunk chunking methods as shown in Table 5.

Table 5T-test of the average number of correct answers in Combined part $(\mathrm{N}=50)$

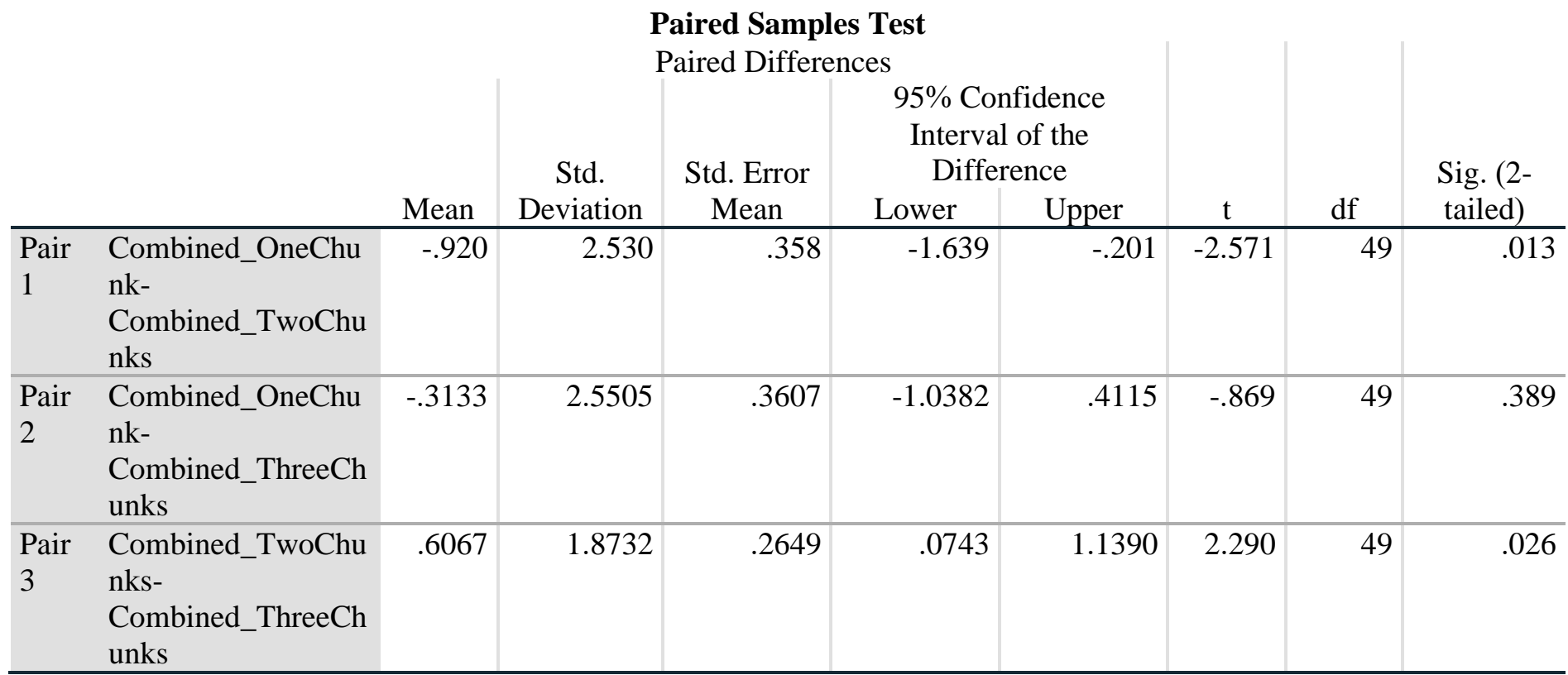

3. Effectiveness of working memory when encountering Three-Chunkchunking methods

Focusing only on the Three-Chunk chunking methods in each experiment, the number of correct answers in the ThreeChunk chunking methods ofthe Letters part and Numbers part were significantly different from that of Combined part as shown in Table 6.

Table 6T-test of the average number of correct answers of all Three-Chunk chunking methods $(\mathrm{N}=50)$

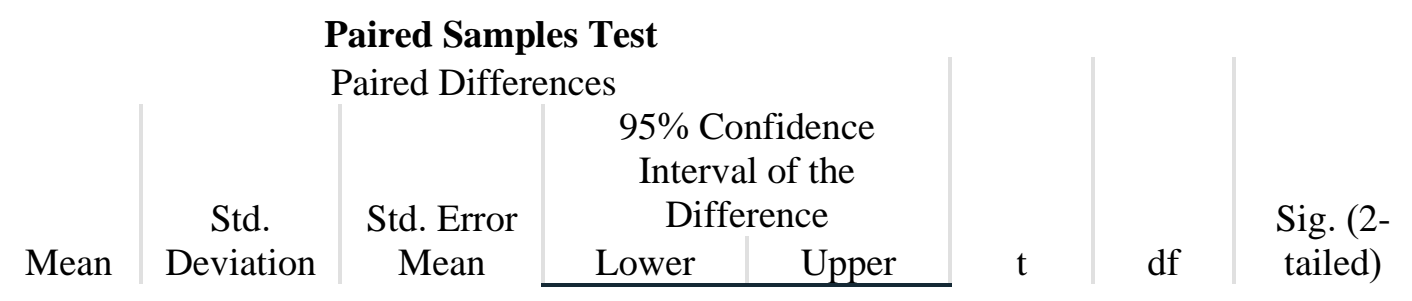




\begin{tabular}{|c|c|c|c|c|c|c|c|c|c|}
\hline $\begin{array}{l}\text { Pair } \\
1\end{array}$ & $\begin{array}{l}\text { Letter_ThreeChunks } \\
- \\
\text { Number_ThreeChun } \\
\text { ks }\end{array}$ & -.4000 & 1.4708 & .2080 & -.8180 & .0180 & -1.923 & 49 & .060 \\
\hline $\begin{array}{l}\text { Pair } \\
2\end{array}$ & $\begin{array}{l}\text { Letter_ThreeChunks } \\
\text { - } \\
\text { Combined_ThreeCh } \\
\text { unks }\end{array}$ & .7000 & 1.4789 & 2091 & .2797 & 1.1203 & 3.347 & 49 & .002 \\
\hline $\begin{array}{l}\text { Pair } \\
3\end{array}$ & $\begin{array}{l}\text { Number_ThreeChun } \\
\text { ks- } \\
\text { Combined_ThreeCh } \\
\text { unks }\end{array}$ & 1.1000 & 1.6960 & .2399 & .6180 & 1.5820 & 4.586 & 49 & .000 \\
\hline
\end{tabular}

\section{$\underline{\text { Discussion }}$}

From this research, it was found that for the information to be accessible into the short-term memory, it must be distinctive and simple in which reassured Cowan's (2008) results. Moreover, by comparing the effectiveness of different forms of information including letters, numbers, and the combination of the aforementioned types, single type of information was found to be easier to recall than the combined types as shown in Table 2. Furthermore, the chunking method, particularly dividing the information into two or three chunks was found to facilitate human memorization. To be more precise, when a single type of information was shown, grouping the information into three chunks was more effective to enhance memorization than providing it in merely one chunk as shown in Table 3 and $\mathbf{4}$. In a similar fashion, when a combined type of information was shown, grouping the information into two chunks was more effective to enhance memorization than providing it in merely one chunk as shown in Table 5. These results were found to support the claim of Darwin \& Crowder, (1972) and Vogel \& Luck (2006) that the optimal number of items in each chunk to maximize memorization was between three to four.

By applying this result into marketing perspectives, it can be used as a theoretical explanation of how advertisements often use two or three adjectives or components in their slogans and advertisements. The rationale underlying it is that in order to make people remember their product, they utilize the effectiveness of chunking by choosing two or three simple and catchy phrases or words that represented their brand to provoke short-term memory that would result in the brand information eventually being processed into people's long-term memory. An example would be how slogans of famous brands such as Airbnb's "Belong Anywhere"
(Gallagher, 2017), Mc Donald's, 'I'm Lovin' It", (Xia, 2020) and KFC's “It's finger-lickin' good", (Husna, et al., 2020), which all had three-word slogans are considered to be three of the most popular and iconic global brands in the industry. Thus, we have coined the term "Three-Chunk effect" to explain the characteristics of how people prioritize and utilize "three things" to strive in various fields of business. In fact, it is advised for people to use these techniques when creating their new platform and wanting other people to acknowledge their brand insights.

Additionally, the results indicate that more learning techniques should be implemented to build these cognitive skills for learners. Various instructional approaches are believed to help students develop chunking skills by themselves such as tree-thinking, computational thinking and binary thinking. Despite the fact that tree thinking is a crucial ability for scientists that could enhance in biology and another general public, it is still not being used enough in education (Novick\&Catley, 2018) Recent researchers argue that by adopting the tree thinking method to help learners learn biology more effectively, their memorization outcomes substantially increase. (Mutiara, et al., 2020; Julaeha, et al., 2020). Moreover, the significance of computational thinking education in the twenty-first century must not be overlooked, as digital computing technologies had emerged into practically all human activities (Threekunprapam\&Yasri, 2020a). In fact, the method has gradually been adopted to improve students' understanding of certain topics (Yadav, et al., 2017). To be more precise, many regions of the world put great attempt to implement this method into students' course including in the United States, Europe, and Asia (Threekunprapam\&Yasri, 2020b). In addition, while binary thinking is mainly used in computer mechanisms (Gatenby, 2017), this tradition of binary thinking is also 
considered a foundation for the numerous forms of structuralism including education (Chalmeau, et al., 2019). Thus, regarding the result of this study, teachers are advised to use the strategy to facilitate students' understanding, hence, improving their ability to memorize new knowledge.

Of course, the intention of this suggestion is not for promoting memorization as an effective mode of learning. It is fully acknowledged that this is rather a lower-ordered thinking skill. However, it is undeniable that our daily life activities involve a certain degree of memorization, and this is the area that we would like to encourage instructors to adopt. Once students can be more effective in memorizing information, this would ease their learning skills in other advanced aspects such as understanding and application of content knowledge.

Furthermore, researchers interested in this strand of research in cognitive psychology may wish to extend the current study to explore the effect of other chunking methods such as 4 chunks or more. This can help advance our current understanding towards the maximum number of chunks that learners can retain within a short period of time. In addition, this study only focuses on single type of textual information, either alphabets or numbers. It is also interesting to see in what ways learners' cognitive capacity would differ if the information is more complicated such as the combination of alphabets and numbers. Lastly, in the future, it would be interesting to conduct further experiments about grouping information into four different chunks for the Letters part, Numbers part and Combined part and compare the results with this research. This is due to the fact that in these experiments, there was a limitation in the quantity of digits (0-9) that could not be divided exactly into four chunks. Hence, by chunking the information more frequently, it would to lead to a depiction of the limitation of number of chunks that could still yield effective results in memorization. Another recommendation would be about studying more about the "Syllable effect". Although every digit has an assigned value, the syllable of pronouncing each word is found to be unequal as seen from the number " 7 " that contains two syllables while the others contain only one. In a similar fashion, this is also the case for the letter "W" that contains three syllables while the others contain only one. Therefore, with a closer scrutinization on this fact, one might be able to relate the neurological difference between remembering digits or letter that have more syllables, thus, more information to remember and the other ordinary ones. In addition, it would be beneficial to find a precise explanation of the chunking method that is dependent in the syllables of words instead of the digits' value or alphabets' type which will eventually enhance the effectiveness of chunking as a whole. Also, by researching more, one might be able to provide a theoretical explanation of how native speakers tend to use abbreviations and slangs in their own language as it might have a connection with how short-term memory are able to work smarter by remembering more subjects in shorter syllables.

\section{Conclusion}

It was evident that for the information to reach the shortterm memory, the information must be unique and straightforward. Moreover, two main findings were found in this study. First, by comparing different types of information, people found single type of information to be easier to recall than the combined types. Second, chunking the information into two and three chunks were found to help people memorize information. If a singe type of information was presented, grouping them into three chunks were found to be more practical than providingall of the information together. Similarly, if it was a combination of the aforementioned types, it was advised to separate them into two chunks. The result could be implemented in marketing perspectives to exemplify the rationale behindchoosing merely two or threewords to define brands. It could also be implicated in education to depict how chunking methods maximize students' learning potentials.

\section{References}

Alloway, T. P., Gathercole, S. E., Adams, A. M., Willis, C., Eaglen, R., \& Lamont, E. (2005).Working memory and phonological awareness as predictors of progress towards early learning goals at school entry.British Journal of Developmental Psychology, 23(3), 417-426.

Alnajjar, K., Kundi, H., \&Toivonen, H. (2018, June)." Talent, Skill and Support.": A Method for Automatic Creation of Slogans. In Proceedings of the Ninth International Conference on Computational Creativity, Salamanca, Spain, June 25-29, 2018.Association for Computational Creativity.

Anderson, M. C., Bjork, R. A., \& Bjork, E. L. (1994). Remembering can cause forgetting: retrieval dynamics in long-term memory. Journal of Experimental Psychology: Learning, Memory, and Cognition, 20(5), 1063.

Baddeley, A. (2000). The episodic buffer: a new component of working memory?.Trends in cognitive sciences, 4(11), 417-423. 
Baddeley, A. (2003). Working memory and language: An overview.Journal of communication disorders, 36(3), 189-208.

Baddeley, A. D., \& Hitch, G. (1974).Working memory.In Psychology of learning and motivation (Vol. 8, pp. 47-89).Academic press.

Baddeley, A. D., \& Warrington, E. K. (1970).Amnesia and the distinction between long-and short-term memory.Journal of verbal learning and verbal behavior, 9(2), 176-189.

Baddeley, A., Gathercole, S., \&Papagno, C. (1998).The phonological loop as a language learning device.Psychological review, 105(1), 158.

Baddeley, A., Logie, R., Bressi, S., Sala, S. D., \&Spinnler, H. (1986).Dementia and working memory.The Quarterly Journal of Experimental Psychology Chunk A, 38(4), 603-618.

Barrouillet, P., Plancher, G., Guida, A., \& Camos, V. (2013). Forgetting at short term: When do eventbased interference and temporal factors have an effect?. Actapsychologica, 142(2), 155-167.

Bers, M. U. (2018). Coding and computational thinking in early childhood: the impact of ScratchJr in Europe. European Journal of STEM Education, 3(3), 8.

Buffalo, E. A., Reber, P. J., \& Squire, L. R. (1998).The human perirhinal cortex and recognition memory.Hippocampus, 8(4), 330-339.

Bullock-Yowell, E., Peterson, G. W., Reardon, R. C., Leierer, S. J., \& Reed, C. A. (2011). Relationships among career and life stress, negative career thoughts, and career decision state: A cognitive information processing perspective. The career development quarterly, 59(4), 302-314.

Cabeza, R., \& Nyberg, L. (2000).Imaging cognition II: An empirical review of 275 PET and fMRI studies.Journal of cognitive neuroscience, 12(1), 147.

Caruso, G., Perri, R., Fadda, L., Caltagirone, C., \&Carlesimo, G. A. (2020). Recall and Recognition in Alzheimer's Disease and Frontotemporal Dementia. Journal of Alzheimer's Disease, (Preprint), 1-12.

Chalmeau, R., Julien, M. P., Calvet, A., Léna, J. Y., \&Mainar, C. V. (2019). Role-play in education for sustainable development to overcome binary thinking: A case study in an elementary school. Education didactique, 13(1), 83-104.

Chen, Z., \& Cowan, N. (2009). Core verbal workingmemory capacity: The limit in words retained without covert articulation. Quarterly journal of experimental psychology, 62(7), 1420-1429.

Clemens, E. V., \& Milsom, A. S. (2008).Enlisted service members' transition into the civilian world of work: A cognitive information processing approach.The Career Development Quarterly, 56(3), 246-256.

Corradini, I., Lodi, M., \& Nardelli, E. (2017, August).Conceptions and misconceptions about computational thinking among Italian primary school teachers. In Proceedings of the 2017 ACM Conference on International Computing Education Research (pp. 136-144).

Cowan, N. (1984). On short and long auditory stores.Psychological bulletin, 96(2), 341.

Cowan, N. (1993). Activation, attention, and short-term memory. Memory \& Cognition, 21(2), 162-167.

Cowan, N. (2001). The magical number 4 in short-term memory: a reconsideration of mental storage capacity. Behav. Brain Sci. 24, 87-185. doi: 10.1017/S0140525X01003922

Cowan, N. (2001). The magical number 4 in short-term memory: A reconsideration of mental storage capacity. Behavioral and brain sciences, 24(1), 87114.

Cowan, N. (2008). What are the differences between long-term, short-term, and working memory?. Progress in brain research, 169, 323338.

Darwin, C. J., Turvey, M. T., \& Crowder, R. G. (1972). An auditory analogue of the Sperling partial report procedure: Evidence for brief auditory storage. Cognitive Psychology, 3(2), 255-267.

Deco, G., \& Rolls, E. T. (2005). Attention, short-term memory, and action selection: a unifying theory. Progress in neurobiology, 76(4), 236-256.

Driscoll, M. P. (1994). Psychology of learning for instruction.Allyn \& Bacon.

Freeman, V. F. (2017). Relationship among FirstGeneration College Student Status and Resilience, Social Support, Perceived Barriers, and Negative Career Thoughts.

Gallagher, L. (2017). The Airbnb Story: How Three Guys Disrupted an Industry, Made Billions of Dollars... and Plenty of Enemies. Random House.

Garavan, H. (1998). Serial attention within working memory. Memory \& cognition, 26(2), 263-276.

Gatenby, A. B. (2017). Developing Critical Understanding of Computing with the Raspberry Pi. International Journal of People-Oriented Programming (IJPOP), 6(2), 1-19. 
Gathercole, S. E., \& Hitch, G. J. (1993). Developmental changes in short-term memory: A revised working memory perspective. Theories of memory, 1, 189209.

Gathercole, S. E., Tiffany, C., Briscoe, J., Thorn, A., \& ALSPAC team. (2005). Developmental consequences of poor phonological short-term memory function in childhood: A longitudinal study. Journal of child Psychology and Psychiatry, 46(6), 598-611.

Gilchrist, A. L. (2015). How should we measure chunks? a continuing issue in chunking research and a way forward. Frontiers in psychology, 6, 1456.

Gilchrist, A. L., \& Cowan, N. (2011). Can the focus of attention accommodate multiple, separate items?.Journal of experimental psychology: learning, memory, and cognition, 37(6), 1484.

Gobet, F. (2005).Chunking models of expertise: Implications for education.Applied Cognitive Psychology, 19(2), 183-204.

Gobet, F., and Clarkson, G. (2004). Chunks in expert memory: evidence for the magical number four...or is it two? Memory 12, 732-747.

Hebb, D. O. (1949).The organization of behavior: a neuropsychological theory. J. Wiley; Chapman \& Hall.

Hintzman, D. L., \& Curran, T. (1994). Retrieval dynamics of recognition and frequency judgments: Evidence for separate processes of familiarity and recall. Journal of Memory and Language, 33(1), 118.

Hunt, E. (1971). What kind of computer is man?.Cognitive Psychology, 2(1), 57-98.

Husna, N., Kee, D. M. H., Amirah, N. W., Syazreeza, R., Fatihah, N. A., Pandey, S., ... \& Pandey, R. (2020). How Organizational Management Affect Employees' Motivation and Service Quality: A Study of Kentucky Fried Chicken (KFC). International Journal of Applied Business and International Management, 5(2), 73-81.

Ibrahim, R., Eviatar, Z., \&Aharon-Peretz, J. (2002). The characteristics of Arabic orthography slow its processing. Neuropsychology, 16(3), 322.

Jackson, D., \& Wilton, N. (2016).Developing career management competencies among undergraduates and the role of work-integrated learning.Teaching in Higher Education, 21(3), 266-286.

James, W. (1890).The principles of.Psychology, 2, 94.

Jarrold, C., \& Baddeley, A. (2001). Short-term memory in Down syndrome: Applying the working memory model. Down syndrome research and practice, 7(1), 17-23.

Jian-jun, H. A. O. (2010). Analysis of" Impossible is nothing" in Adidas' Advertisement Slogan from Functional Stylistics. Journal of Yibin University, (9), 24.

Jing, J., Qi, M., Gao, H., \& Zhang, Q. (2019). The role of forgetting cues in directed forgetting: Ceasing maintenance rehearsal. Actapsychologica, 199, 102922.

Jonides, J., Lewis, R. L., Nee, D. E., Lustig, C. A., Berman, M. G., \& Moore, K. S. (2008). The mind and brain of short-term memory.Annu. Rev. Psychol., 59, 193-224.

Julaeha, S., Hidayat, T., \&Rustaman, N. Y. (2020). Development of web-based three tier multiple choice test to measure student's tree thinking; try out. In Journal of Physics: Conference Series (Vol. 1521, p. 042024).

Kroll, N. E., Parks, T., Parkinson, S. R., Bieber, S. L., \& Johnson, A. L. (1970). Short-term memory while shadowing: Recall of visually and of aurally presented letters. Journal of Experimental Psychology, 85(2), 220.

Kronholz, J. F., \& Osborn, D. S. (2016).The Impact of Study Abroad Experiences on Vocational Identity among College Students.Frontiers: The Interdisciplinary Journal of Study Abroad, 27, 7084.

Kruger, A. J. (2008). Preaching Christ from Genesis. Foundations for Expository Sermons, Sidney Greidanus: book review. Dutch Reformed Theological Journal= NederduitseGereformeerdeTeologieseTydskrif, 49( 1_2), 289-292.

Lachman, R., Lachman, J. L., \& Butterfield, E. C. (2015).Cognitive psychology and information processing: An introduction. Psychology Press.

Lane, P. C., Gobet, F., \& Cheng, P. C. (2001). What forms the chunks in a subject's performance? Lessons from the CHREST computational model of learning.Behavioral and Brain Sciences, 24(1), 128-129.

Lauwaert, M. (2007). Challenge everything? Construction play in Will Wright's SIMCITY. Games and Culture, 2(3), 194-212.

Lorenz, D., \&Tizón-Couto, D. (2019).Chunking or predicting-frequency information and reduction in the perception of multi-word sequences.Cognitive Linguistics, 30(4), 751-784. 
Mahmood, S. (2009). Feminism, democracy, and empire: Islam and the war on terror. In Gendering Religion and Politics (pp. 193-215). Palgrave Macmillan, New York.

Majerus, S., Poncelet, M., Christelle, G., Van der Linden, M., "Relations between vocabulary development and verbal short-term memory: The relative importance of short-term memory for serial order and item information." Journal of experimental child psychology 93.2 (2006): 95-119.

Majerus, S., Poncelet, M., Van der Linden, M., \& Weekes, B. S. (2008). Lexical learning in bilingual adults: The relative importance of short-term memory for serial order and phonological knowledge. Cognition, 107(2), 395-419.

Makizako, H., Shimada, H., Park, H., Doi, T., Yoshida, D., Uemura, K., ...\& Suzuki, T. (2013). Evaluation of multidimensional neurocognitive function using a tablet personal computer: Test-retest reliability and validity in community-dwelling older adults. Geriatrics \& gerontology international, 13(4), 860-866.

Martina, D. E. (2018). The Effect of Using PQ4R (Preview, Question, Read, Reflect, Recite, Review) Strategy on EFL Students' Reading Comprehension Achievement. Research in English and Education Journal, 3(1), 17-24.

Mathy, F., and Feldman, J. (2012). What's magic about magic numbers? Chunking and data compression in short-term memory.Cognition 122, 346-362.

Mayer, R. E. (2003). Elements of a science of elearning.Journal of Educational Computing Research, 29(3), 297-313.

McElree, B. (2006). Accessing recent events. Psychology of learning and motivation, 46, 155-200.

McElree, B., \&Dosher, B. A. (2001). The focus of attention across space and across time.Behavioral and Brain Sciences, 24(1), 129.

Michalik, U., \&Michalska-Suchanek, M. (2016).The persuasive function of rhetoric in advertising slogans. Journal of Accounting and Management, 6(1), 45-58.

Miller, G. A. (1956). The magical number seven, plus or minus two: Some limits on our capacity for processing information. Psychological review, 63(2), 81.

Mitchell, K. J., \& Hill, E. M. (2019).The impact of focusing on different features during encoding on young and older adults' source memory. Open Psychology, 1(1), 106-118.
Murray, D. J. (2001). Partial matching theory and the memory span. Behavioral and Brain Sciences, 24(1), 133-134.

Mutiara, E., Juhanda, A., \&Ramdhan, B. (2020). The Emergence Profile of Tree Thinking of Senior High School Students Through the Inquiry Based Learning. JurnalMangiferaEdu, 5(1), 18-25.

Nemÿoková, K. (2011). Translating Slogans: Advertising Campaigns Across Languages. Beyond Borders: Translations Moving Languages, Literatures and Cultures, 39, 59.

Newell, A., \& Simon, H. A. (1972).Human problem solving (Vol. 104, No. 9). Englewood Cliffs, NJ: Prentice-Hall.

Novick, L. R., \&Catley, K. M. (2018). Teaching tree thinking in an upper level organismal biology course: Testing the effectiveness of a multifaceted curriculum. Journal of Biological Education, 52(1), 66-78.

Osborn, D. S., Dozier, C., Peterson, G. W., BullockYowell, E., Saunders, D. E., \& Sampson Jr, J. P. (2018). 5 Cognitive information processing theory.Contemporary Theories of Career Development: International Perspectives.

Parington, J. E., \&Lieter, R. G. (1949).Parington's pathway test.The Psychological Service Center Bulletin, 1, 9-20

Parrila, R., Kirby, J. R., \& McQuarrie, L. (2004). Articulation rate, naming speed, verbal short-term memory, and phonological awareness: Longitudinal predictors of early reading development?. Scientific studies of reading, 8(1), 3-26.

Parsons, F. (1909).Choosing a vocation.Houghton Mifflin.

Phaf, R. H., \& Wolters, G. (1993). Attentional shifts in maintenance rehearsal. The American journal of psychology, 353-382.

Phillips, I. B. (2011). Perception and iconic memory: what Sperling doesn't show. Mind \& Language, 26(4), 381-411.

Pignatelli, M., Ryan, T. J., Roy, D. S., Lovett, C., Smith, L. M., Muralidhar, S., \&Tonegawa, S. (2019). Engram cell excitability state determines the efficacy of memory retrieval. Neuron, 101(2), 274284.

Reardon, R. C., Lenz, J. G., Sampson Jr, J. P., \& Peterson, G. W. (2011). Big questions facing vocational psychology: A cognitive information processing perspective. Journal of Career Assessment, 19(3), 240-250. 
Repovš, G., \& Baddeley, A. (2006). The multicomponent model of working memory: Explorations in experimental cognitive psychology. Neuroscience, 139(1), 5-21.

Sampson Jr, J. P., Lenz, J. G., Reardon, R. C., \& Peterson, G. W. (1999). A cognitive information processing approach to employment problem solving and decision making.The Career Development Quarterly, 48(1), 3-18.

Sampson Jr, J. P., Peterson, G. W., Reardon, R. C., \& Lenz, J. G. (2003). Key elements of the CIP approach to designing career services. Center for the Study of Technology in Counseling and Career Development, Tallahassee, FL: Florida State University.

Schneider, W. X., Deubel, H., \&Wesenick, M. B. (2001). Characterizing chunks in visual short-term memory: Not more than one feature per dimension?.Behavioral and Brain Sciences, 24(1), 144-145.

Schunk, D. H. (1996).Learning theories.Printice Hall Inc., New Jersey, 53.

Shallice, T., \&Papagno, C. (2019). Impairments of auditory-verbal short-term memory: Do selective deficits of the input phonological buffer exist?.Cortex, 112, 107-121.

Shallice, T., \& Warrington, E. K. (1970). Independent functioning of verbal memory stores: A neuropsychological study. The Quarterly journal of experimental psychology, 22(2), 261-273.

Shiffrin, R. M., \& Atkinson, R. C. (1969). Storage and retrieval processes in long-term memory. Psychological Review, 76(2), 179.

Smith, E. E., Jonides, J., Koeppe, R. A., Awh, E., Schumacher, E. H., \&Minoshima, S. (1995). Spatial versus object working memory: PET investigations. Journal of cognitive neuroscience, 7(3), 337-356.

So, H. J., Jong, M. S. Y., \& Liu, C. C. (2020).Computational thinking education in the Asian Pacific region.

Sokolovsky, Y. V. (2012). Correlation between the Original and Translation of Advertising Slogans: Translational Autonomy and Equivalence. ЖурналСибирскогофедеральногоун иверситета.Серия: Гуманитарныенауки, 5(6), 868-873.

Sperling, G. (1960). The information available in brief visual presentations.Psychological monographs: General and applied, 74(11), 1.
Tallon-Baudry, C., Bertrand, O., \& Fischer, C. (2001).Oscillatory synchrony between human extrastriate areas during visual short-term memory maintenance. Journal of Neuroscience, 21(20), RC177-RC177.

Talmi, D., Grady, C. L., Goshen-Gottstein, Y., \&Moscovitch, M. (2005). Neuroimaging the serial position curve: A test of single-store versus dualstore models. Psychological Science, 16(9), 716723.

Tasnim, M. (2018).An Organizational Analysis on Apple. European Journal of Business and Management, 10(11).

Threekunprapa, A., \&Yasri, P. (2020).Unplugged Coding Using Flowblocks for Promoting Computational Thinking and Programming among Secondary School Students.International Journal of Instruction, 13(3), 207-222.

Threekunprapam, A., \&Yasri, P. (2020). Patterns of Computational Thinking Development While Solving Unplugged Coding Activities Coupled with the 3S Approach for Self-Directed Learning. European Journal of Educational Research, 9(3), 1025-1045.

Todd, J. J., \&Marois, R. (2004).Capacity limit of visual short-term memory in human posterior parietal cortex. Nature, 428(6984), 751-754.

Tomlin, C. (2020). The Hermeneutics of African Caribbean Homiletics. The Future Shape of Christian Proclamation: What the Global South Can Teach Us About Preaching, 92.

Tulving, E., \&Patkau, J. E. (1962).Concurrent effects of contextual constraint and word frequency on immediate recall and learning of verbal material.Canadian Journal of Psychology/Revue canadienne de psychologie, 16(2), 83.

Vigneron, F., \& Johnson, L. W. (1999).A review and a conceptual framework of prestige-seeking consumer behavior. Academy of marketing science review, 1(1), 1-15.

Vogel, E. K., Woodman, G. F., \& Luck, S. J. (2006).The time course of consolidation in visual working memory. Journal of Experimental Psychology: Human Perception and Performance, 32(6), 1436.

Wang, S., Wang, X., Wang, S., \& Wang, D. (2019).Bidirectional long short-term memory method based on attention mechanism and rolling update for short-term load forecasting. International Journal of Electrical Power \& Energy Systems, 109, 470479. 
Wells, P. (2019). Just Do It, Impossible Is Nothing: Animation and Sports Commercials. In Animation and Advertising (pp. 179-193). Palgrave Macmillan, Cham.

Wilding, J. (2001). Over the top: Are there exceptions to the basic capacity limit?.Behavioral and Brain Sciences, 24(1), 152-153.

Wong, K. W. G., Ching, C. C., Mark, K. P., Tang, J. K., Lei, C. U., Cheung, H. Y., \& Chui, H. L. (2015). Impact of computational thinking through coding in K-12 education: A pilot study in Hong Kong. General Studies, 85(88.01), 2-08.
Xia, J. (2020, November). Linguistic Realizations of Metadiscourse in Advertising Slogans: A Case Study of McDonald's. In 2020 5th International Conference on Modern Management and Education Technology (MMET 2020) (pp. 696699).Atlantis Press.

Yadav, A., Gretter, S., Good, J., \& McLean, T. (2017).Computational thinking in teacher education.In Emerging research, practice, and policy on computational thinking (pp. 205220).Springer, Cham.

\begin{tabular}{|c|c|c|c|c|c|c|c|c|c|c|c|c|}
\hline \multirow{2}{*}{\multicolumn{3}{|c|}{ Experiments }} & \multicolumn{10}{|c|}{ Digits } \\
\hline & & & 1 & \multirow{2}{*}{$\frac{2}{7}$} & \multirow[t]{2}{*}{3} & \multirow[t]{2}{*}{4} & \multirow{2}{*}{$\begin{array}{l}5 \\
8\end{array}$} & \multirow{2}{*}{$\begin{array}{l}6 \\
2\end{array}$} & \multirow[t]{2}{*}{7} & \multirow{2}{*}{$\frac{8}{4}$} & \multirow{2}{*}{$\begin{array}{l}9 \\
1\end{array}$} & \multirow{2}{*}{$\begin{array}{c}\mathbf{1 0} \\
0\end{array}$} \\
\hline & One-Chunk & & 3 & & & & & & & & & \\
\hline & Two-Chunk & & 8 & 5 & 7 & 3 & 1 & 4 & 6 & 2 & 0 & 9 \\
\hline \multirow[t]{5}{*}{ Letters } & & $4-3-3$ & 2 & 6 & 9 & 5 & 8 & 0 & 4 & 7 & 1 & 3 \\
\hline & Three-Chunk & $3-4-3$ & 9 & 6 & 2 & 1 & 4 & 7 & 5 & 3 & 0 & 8 \\
\hline & & $3-3-4$ & 5 & 1 & 8 & 4 & 7 & 9 & 0 & 2 & 6 & 3 \\
\hline & One-Chunk & & G & $\mathrm{H}$ & $S$ & A & $\mathrm{C}$ & $\mathrm{L}$ & B & $\mathrm{O}$ & Q & $\mathrm{D}$ \\
\hline & Two-Chunk & & $\mathrm{H}$ & M & $\mathrm{A}$ & $\mathrm{L}$ & $\mathrm{C}$ & Q & $\mathrm{J}$ & $\mathrm{W}$ & $\mathrm{F}$ & $\mathrm{X}$ \\
\hline \multirow[t]{5}{*}{ Numbers } & & $4-3-3$ & I & M & $\mathrm{G}$ & $\mathrm{Y}$ & $\mathrm{J}$ & $\mathrm{V}$ & $\mathrm{C}$ & $\mathrm{L}$ & $\mathrm{S}$ & A \\
\hline & Three-Chunk & $3-4-3$ & $\mathrm{P}$ & $\mathrm{L}$ & $\mathrm{G}$ & $\mathrm{O}$ & $\mathrm{D}$ & $\mathrm{H}$ & $\mathrm{V}$ & $\mathrm{U}$ & $\mathrm{B}$ & I \\
\hline & & $3-3-4$ & B & $\mathrm{Y}$ & I & V & $\mathrm{W}$ & $\mathrm{C}$ & $\mathrm{H}$ & $\mathrm{D}$ & $\mathrm{K}$ & M \\
\hline & One-Chunk & & B & 6 & $\mathrm{~N}$ & 3 & $\mathrm{~L}$ & 7 & $\mathrm{~J}$ & 1 & $\mathrm{D}$ & 8 \\
\hline & Two-Chunk & & $\mathrm{C}$ & 9 & M & 2 & A & 5 & $\mathrm{~K}$ & 3 & I & 7 \\
\hline \multirow[t]{3}{*}{ Combined } & & $4-3-3$ & $\mathrm{Y}$ & 4 & I & 9 & 0 & 3 & G & 5 & $\mathrm{P}$ & 1 \\
\hline & Three-Chunk & $3-4-3$ & $\mathrm{~N}$ & 7 & $\mathrm{~T}$ & 2 & B & 9 & $S$ & 1 & $\mathrm{X}$ & 6 \\
\hline & & $3-3-4$ & $\mathrm{U}$ & 2 & $\mathrm{H}$ & 4 & $\mathrm{~S}$ & 1 & $\mathrm{Q}$ & 8 & $\mathrm{~W}$ & 0 \\
\hline
\end{tabular}

\section{Appendix A: Evaluation Form Key}

